\title{
REABILITAÇÃO PROFISSIONAL NA ÁREA DA SAÚdE MENTAL: INTERLOCUÇÕES COM A ANTROPOLOGIA DA SAÚDE
}

\author{
Valéria Morais da Silveira Sousa ${ }^{1}$ \\ Francinaldo do Monte Pinto ${ }^{2}$ \\ Thelma Maria Grisi Velôso ${ }^{3}$
}

\section{Introdução}

Falar da reabilitação profissional, no campo da saúde mental, remete, invariavelmente, ao processo de trabalho-saúde-doença e à abertura de uma discussão, que não se pretende esgotada, sobre os Transtornos Mentais e Comportamentais (TMC) como motivos de afastamento do trabalho (Esponda, 2012; Seligman-Silva, 2009), confirmado pelo Anuário Estatístico de Acidentes de Trabalho (2017), entre os acidentes de trabalho, segundo a Classificação Internacional de Doenças - CID-10, mais incidentes no Brasil no período de 2015 a 2017 (Brasil, 2017).

Neste artigo, adotou-se a terminologia Transtornos Mentais e Comportamentais, por ser a nomenclatura utilizada na Classificação Internacional de Doenças (CID-10) e, por conseguinte, pelo programa gerenciado pelo Instituto Nacional do Seguro Social (INSS), responsável por coordenar a reabilitação profissional no Brasil, embora se reconheça que esse dispositivo (CID-10) tem sido utilizado nos processos diagnósticos e, em muitas situações, legitimado a hegemonia de um modelo mecanicista que preconiza o saber médico como único e absoluto. Um saber que pode, via de regra, culpabilizar o próprio sujeito pelo adoecimento, ao invés de reconhecer seu saber sobre si mesmo, como um elemento integrante e relevante para compreender seu estado, inclusive, porque a conclusão pode apresentar mais indicativos de saúde do que de doença, conforme pondera Canguilhem (2017:142):

\footnotetext{
${ }^{1}$ Universidade Estadual da Paraíba, Brasil. Email: valeriamorais1803@hotmail.com ORCID id: https://orcid.org/0000-0002-9609-7083

${ }^{2}$ Universidade Estadual da Paraíba, Brasil. Email: dumontepinto@uol.com.br ORCID id : https://orcid.org/0000-0001-9597-2870

${ }^{3}$ Universidade Estadual da Paraíba, Brasil. Email: thelma_veloso@yahoo.com.mx ORCID id : https://orcid.org/0000-0003-0447-7490
} 
Ao contrário de certos médicos, sempre dispostos a considerar as doenças como crimes, porque os interessados sempre são, de certa forma, responsáveis, por excesso ou omissão, achamos que o poder e a tentação de se tornar doente são uma característica essencial da fisiologia humana. Transpondo uma frase de Valéry, dissemos que a possibilidade de abusar da saúde faz parte da saúde.

Se tal contexto já se apresenta denso, muito mais, quando relacionado ao trabalho, por se tratar de um universo enigmático e intrinsecamente presente na vida humana, além de complexo em seu sentido, posto que sofre variações ao longo do tempo e de uma sociedade para outra (Lancman; Barros; Jardim, 2016). Nesse sentido, Lacaz (2003) ressalta que as exigências atuais do mundo do trabalho incidem, de forma contraditória, na saúde do trabalhador: exigem-se, ao mesmo tempo, a intensificação do ritmo de trabalho, o controle e o conhecimento. A influência do trabalho sobre o processo saúde/doença, a exemplo do aumento do estresse relacionado ao trabalho, configura-se uma importante causa dos TMC. O referido autor pontua que

importa, então, desvendar a nocividade do processo de trabalho sob o capitalismo e suas implicações: alienação; sobrecarga e/ou subcarga; pela interação dinâmica de "cargas" sobre os corpos que trabalham, conformando um nexo biopsíquico que expressa o desgaste impeditivo da fluição das potencialidades e da criatividade (Lacaz, 2007: 759, grifo do autor).

É importante salientar que a relação entre trabalho, saúde e doença é intrínseca às mudanças no mundo do trabalho, as quais têm sido alvo de pesquisas e de estudos que apontam para o aumento do desemprego e a progressiva degradação das condições de trabalho, tanto no Brasil como no mundo (Lancman, 2004). Corroborando essa afirmação, Salazar (2012), ao tratar da precarização do trabalho, em particular, na América Latina, aponta algumas causas, como a fragmentação produtiva e a flexibilização da produção e do trabalho, somada com a desregulação jurídica e uma regressão dos direitos sociais e laborais.

De acordo com Antunes (2014), a degradação típica do taylorismo e do fordismo, que vigorou ao longo de praticamente todo o Século $\mathrm{XX}$, embora tenha (ainda) um desenho mais acentuadamente despótico, caracteriza-se por ser mais regulamentado e contratualista. Apesar de imerso em um universo mecanicista, é provido de direitos e regulamentação ao menos para seus polos mais qualificados. Ocorre que passa a surgir uma nova forma de degradação do trabalho introduzida por meio do modelo orquestrado pela flexibilidade toyotista, que traz consigo uma aparência de mais participação do trabalhador e da trabalhadora em todo o processo de 
produção, utilizando os chamados trabalhos em equipe, células de produção, times de trabalho, entre outras expressões e práticas que preservam, em sua essência, o modelo predominantemente controlador e coercitivo da gestão taylorista/fordista.

Essas mudanças apontam para uma nítida relação dos impactos desses novos modos de produzir na relação entre saúde, trabalho e doença, apesar do esforço das organizações de apresentarem um discurso que tenta naturalizar o adoecimento e, ao mesmo tempo, dissociá-lo de qualquer possível relação com o modus operandi que se caracteriza, entre outros aspectos, pela hipersolicitação do trabalhador e da trabalhadora, tanto física quanto mental/psicologicamente, promovendo o que Alves (2011: 111) afirma ser a "captura da subjetividade do trabalho pela lógica do capital", porquanto os dispositivos utilizados não se prestam somente a controlar a atuação da classe trabalhadora, conforme os modelos anteriores - taylorismo e fordismo - mas também, sobretudo, a exercer uma influência velada ao ponto de produzir um sentimento de pertencimento que induz, individualmente, a um nível de envolvimento denominado de comprometimento, proatividade, iniciativa ou expressões como: "vestir a camisa da empresa". Assim, a inspeção e a supervisão do trabalho passam a ser do/a próprio/a trabalhador/a, invocando um nível de exigência pessoal, muitas vezes, insuportável.

Estudos têm demonstrado a relação entre o desenvolvimento de organização flexível do trabalho e emprego e o aumento de patologias de hiper solicitação (as chamadas lesões por esforços repetitivos - LER) até as descompensações psíquicas (Hirata, 2007; Franco; Druck; Seligmann-Silva, 2010; Barbosa, 2014; Antunes; Praun, 2015). A esse respeito, é mister pontuar o destaque para o adoecimento psíquico como resultante da flexibilidade imposta nas relações de trabalho, que traz um contexto de intensa instabilidade tanto no que se refere às regras de trabalho, porque elas oscilam em detrimento das constantes mudanças na dinâmica mercadológica, quanto no que se refere à desregulamentação dos contratos de trabalho. Nesse sentido, Seligman-Silva (2011) considera que as exigências relativas ao trabalho mental são a marca das profundas transformações que o trabalho humano atravessa.

$\mathrm{Na}$ essência desta discussão, é importante localizar os aspectos relativos ao desmonte da proteção social aos trabalhadores e trabalhadoras nos últimos anos e que tem sido vivenciado no Brasil, e em toda a América Latina, por sucessivas mudanças advindas de deliberações governamentais, reforçando esse cenário e apresentando 
contornos explícitos da crise do modelo neoliberal. Desde o ano de 2016, no Brasil, a partir da evidente expressão de ataque às conquistas da classe trabalhadora quanto aos direitos trabalhistas e de proteção social, e como desdobramento do golpe de Estado sofrido pelo então governo da Presidente Dilma Russeff, diversas ações têm sido empreendidas no sentido não só de fragilizar, como também de tornar a classe trabalhadora desprovida de qualquer suporte e cada vez mais dependente das forças do capital. É inegável que essa realidade, também permeada pela terceirização e pela precarização do trabalho, esta última intensificada por meio do trabalho temporário e do trabalho em tempo parcial (Silva, 2019), incrementa a situação de adoecimento físico e mental da classe trabalhadora.

No Brasil, parte dos trabalhadores/trabalhadoras acometidos/as de enfermidade ou acidente relacionado ao trabalho e, por esse motivo, afastados de sua atividade laboral, são acompanhados pelo Instituto Nacional do Seguro Social (INSS), por meio do Programa Reabilita, que, de acordo com Maeno e Vilela (2010), tem sofrido diversas modificações desde o seu início. Sua principal característica é a recolocação ou o retorno do trabalhador/a ao local de trabalho, sob o acompanhamento institucional de orientadores profissionais. A partir de um modelo processual padrão, que compreende a ação do Estado através do INSS, da empresa de origem do trabalhador/trabalhadora e destes últimos, é que a reabilitação profissional acontece, inclusive quando o motivo do afastamento é relacionado aos TMC.

Neste artigo, objetiva-se apresentar uma reflexão teórica atenta às interfaces existentes entre a reabilitação profissional e a saúde mental, sob a perspectiva da Antropologia da Saúde, que repousa em duas bases: a primeira diz respeito ao fundamento da visão antropológica que preconiza o deslocamento do olhar sobre o corpo das ciências médicas para o olhar da construção social e relacional do corpo. A segunda é relativa à perspectiva desse campo de estudo. Langdon (2014), amparando-se na compreensão de que a Antropologia da Saúde é uma interdisciplina - que produz conhecimentos na interface entre as ciências médicas e as ciências sociais - corrobora a visão de Minayo (1998), para quem, embora existam críticas à interdisciplinaridade, por ser uma possível articulação de fragmentos, os ganhos são maiores do que as perdas. Como ressalta Sarti (2010), não se trata de considerar a interdisciplinaridade na perspectiva de identificar diferentes saberes, mas de reconhecer que o encontro desses 
saberes só é possível se forem consideradas as fronteiras que os afastam, os tencionam e os aproximam. Nesse sentido, o encontro supõe a separação. É preciso não desconsiderar que o saber biomédico ${ }^{4}$ ocupa, nas sociedades ocidentais, um lugar privilegiado. A medicina nos interpela constantemente e, “onipresente, vem nos dizer não apenas como curar nossas doenças ou aliviar nosso sofrimento, mas, propriamente, como viver." (Sarti, 2010: 78).

Acredita-se que o crescimento das pesquisas antropológicas em temas relacionados à saúde (Langdon; Follér; Maluf, 2012; Canesqui, 2003; Langdon, 2014), particularmente no Brasil, respalda tanto a relevância quanto a possibilidade de a antropologia da saúde fortalecer a noção de saúde e sustentar as políticas públicas. Marroni (2007: 103) assevera que a

Antropologia da Saúde permite examinar as relações entre os modelos de prática, que suportam a organização dos serviços, os programas de prevenção, as intervenções terapêuticas, e os modelos culturais dos usuários. A partir daí ela fornece parâmetros para a reformulação da questão da adequação sociocultural dos diferentes programas de saúde.

Ampliando essa visão, a América Latina apresenta um cenário que favorece a compreensão de que a Antropologia da Saúde vem se constituindo, cada vez mais, como uma profícua área do conhecimento capaz de clarificar os meandros do processo saúde/doença. É importante ressaltar que seu objetivo central precisa estar relacionado à situação socioeconômica e sociopolítica dos nossos países, assim como aos momentos históricos em que se desenvolvem (Menendéz, 2018). Essa relação é inevitável, porque "a distribuição do estado de saúde e do acesso aos serviços de atenção à saúde entre os diversos grupos socioeconômicos segue padrões que colocam os grupos mais vulneráveis em situação de desvantagem contínua" (Dachs; Bambas; Casas, 2005:332). Em revisão acerca da Antropologia Médica (terminologia ainda utilizada) na América Latina, no período de 1990 a 2015, Menendéz (2018) identificou vinte categorias de estudo e, em seus achados, embora se verifique a presença da saúde mental, não há relação direta com a reabilitação profissional.

\footnotetext{
${ }^{4}$ O modelo biomédico clássico denota uma compreensão dos fenômenos de saúde e doença com base nas ciências da vida, a partir da Biologia. Nessa abordagem, a doença é definida como desajuste ou falta de mecanismos de adaptação do organismo ao meio ou como uma presença de perturbações da estrutura viva, causadoras de desarranjos na função de um órgão, sistema ou organismo. É tratado também como um modelo unicausal (Puttini et al., 2010).
} 
Uma ampliação do olhar sobre a Reabilitação Profissional em Saúde Mental, a partir da perspectiva antropológica, levando em consideração os aspectos relacionados à cultura, ao corpo, a uma concepção de saúde ampliada e que leva em conta a experiência e a construção sociocultural, além das dimensões interacional e política, poderá contribuir para uma reflexão que não se pretende conclusiva, contudo provocativa, no sentido de ser parte de um gatilho que possa alavancar o protagonismo dos sujeitos imersos nesse universo.

Neste artigo, a discussão acontecerá a partir do significado da reabilitação profissional no Brasil, discorrendo com brevidade sobre suas bases, trajetória e desafios. Em seguida, faremos uma reflexão sobre saúde e saúde mental no trabalho, as influências das mudanças no(s) mundo(s) do trabalho sobre a saúde física e mental e seus desdobramentos e, por fim, um diálogo (necessário) entre Antropologia da Saúde e Reabilitação Profissional em Saúde Mental como um dispositivo possível para fortalecer as políticas públicas em saúde mental do/a trabalhador/a no Brasil.

\section{Reabilitação profissional: o que é?}

A Organização Mundial de Saúde - OMS - afirma que a reabilitação é “um conjunto de medidas que ajudam pessoas com deficiências ou prestes a adquirir deficiências a terem e manterem uma funcionalidade ideal na interação com seu ambiente" (OMS, 2011: 100). Por mais que a expressão 'funcionalidade ideal', na prática, se mantenha, em muitas circunstâncias, distante da realidade, a ideia de interagir com o ambiente emerge como um importante alvo a ser alcançado pela reabilitação. Quando envolta pelo mundo do trabalho, ganha contornos característicos desse complexo universo, como a dificuldade de (re)inserção no mercado de trabalho. A aprovação de leis que garantam a pessoas com "deficiência" ou perda de potencial laborativo sua inserção no mercado de trabalho, constitui-se uma importante e disseminada estratégia dos países da América Latina (Santos, 2017: 844). Segundo o referido autor, a América Latina apresenta realidades singulares e desafios comuns no que diz respeito à inserção dessas pessoas em mercados cuja competitividade e exigências são cada vez maiores. Contudo, constatam-se experiências bem sucedidas, 
principalmente no Brasil, no Chile, na Colômbia, em Costa Rica, no Equador, no México e no Peru.

No Brasil, a fundamentação legal que ampara as ações da reabilitação profissional está baseada na própria Constituição Federal de 1988, em seu Art. 203, incisos II e IV, como também na Lei 8.213/91, Arts. 89 a 93 (Ibrahim, 2012). Destaca-se o artigo 89, ao afirmar que a habilitação e a reabilitação profissional e social deverão proporcionar ao beneficiário incapacitado para o trabalho, parcial ou totalmente, e às pessoas portadoras de deficiência, os meios para a (re)educação e a (re)adaptação profissional e social indicados para participarem do mercado de trabalho e do contexto em que vivem.

De acordo com a Lei 8.213/91, estão aptos a participar do programa os dependentes com mais de 16 anos com alguma deficiência, os aposentados por invalidez, espontaneamente ou quando da revisão do benefício, os dependentes pensionistas inválidos e as pessoas com deficiência, sem vínculo com a previdência, mediante convênio de cooperação técnico-financeira com instituições ou empresas (Simonelli et al., 2010). Também é garantido aos trabalhadores em reabilitação o fornecimento de aparelhos, como próteses e órteses, entre outras condições para a participação em cursos de qualificação visando a possível vida ativa do beneficiário no mercado de trabalho.

O processo de reabilitação profissional atribuído INSS sofreu impactos substanciais com as mudanças nas esferas política e econômica, em relação ao modelo neoliberal de desenvolvimento, que, entre outras práticas, preconiza a diminuição do papel do Estado na execução de algumas políticas públicas para a condição de agente regulador (Takahashi; Iguti, 2008). Para as autoras, entre outras consequências das ações neoliberais, destaca-se o desmonte da rede de proteção social, em que as instituições previdenciárias passaram a ser alvos de expressivas mudanças estruturais.

Takahashi (apud Maeno; Vilela, 2010) apresenta três fases do processo de mudanças ocorridas na reabilitação profissional do INSS, depois da Constituição Federal de 1988. A primeira, entre 1993 e 1994, caracterizada por questionamentos aos modelos estruturais centralizados e aos conceitos que consideravam a incapacidade diretamente relacionada à doença ou ao trauma, exigia, essencialmente, a assistência médica individual. Já a segunda, entre os anos de 1995 e 2000, simbolizada pelo Plano 
de Modernização da Reabilitação Profissional do INSS, consolidou a hegemonia do modelo reducionista de atenção, de delegação da administração da reinserção no trabalho nas empresas e o desmonte dos Centros de Reabilitação Profissional (CRPs) e dos Núcleos de Reabilitação Profissional (NRPs), já em fase de decadência. Por fim, a terceira fase foi marcada pela implantação do Programa Reabilita, no ano de 2001, até os dias atuais, fundamentada no regulamento da Previdência Social, em que a recolocação fica a cargo de orientadores profissionais e, não mais, de equipes de reabilitação profissional (Maeno; Vilela, 2010).

Em 2014, o INSS divulgou uma consulta pública sobre reabilitação profissional, a fim de receber contribuições para um projeto intitulado Reabilitação Profissional: articulando ações em saúde do trabalhador e construindo a reabilitação integral. $\mathrm{O}$ projeto apresenta, em sua justificativa, a conceituação de RP como uma ação estratégica que visa possibilitar o cumprimento do objetivo - aprimorar a prevenção de riscos ocupacionais e mitigar os efeitos da incapacidade laboral, inscritos no Mapa Estratégico da Previdência Social 2012-2015, ao mesmo tempo em que apresenta interface com a Política Nacional de Segurança e Saúde no Trabalho (PNSST) e as Políticas de Seguridade Social, dentre outras (Brasil, 2014).

Como objetivo principal, o Reabilita (denominação do atual programa do INSS) visa promover ações de reabilitação profissional, integradas às políticas de Seguridade Social por meio de uma rede de reabilitação articulada, descentralizada e estruturada no âmbito dos entes federados, com vistas à inclusão na sociedade, por meio do seu efetivo ingresso ou reingresso no mundo do trabalho. O projeto sinaliza um possível passo em direção a mudanças necessárias e efetivas que favoreçam diretamente o trabalhador lesionado por ocasião do seu retorno ao trabalho.

Essas considerações corroboram o pensamento de Takahashi e de Iguti (2008), quando afirmam que as reformas na Previdência Social ocorridas no Brasil, entre as décadas de 1990 e 2000, não puderam dar conta dos principais problemas diagnosticados pela Comissão Interministerial de Saúde do Trabalhador de 1993, a considerar a seguinte realidade: os segurados continuam sem receber o tratamento a eles devido, uma vez que são vistos como não cidadãos, afirmam as referidas autoras. Além disso, salientam a manutenção de uma fragmentação institucional, porquanto as instituições públicas que fazem interface com a saúde do trabalhador - Ministério da 
Saúde, Ministério da Previdência Social e Ministério do Trabalho - seguem atuando de forma desarticulada e com baixo poder de intervenção no poderio das empresas.

Ao se fazer uma incursão no modelo vigente da Reabilitação Profissional e seus objetivos expressos na lei que a regula, percebe-se que a direção do movimento ali descrito é vertical, porquanto se vê o trabalhador como um elemento dessa estrutura, que deve enquadrar-se em uma sequência de atos predeterminados (institucionalmente) e redundar em sua reabilitação profissional.

A descrição acima sobre a reabilitação profissional no Brasil, via 'Programa Reabilita', vinculado ao INSS, provoca reflexões que evocam as concepções de indivíduo e pessoa apontadas por Duarte (2003) ao mesmo tempo em que dialogam com o estudo de Minayo (2001), que problematiza conceitos como estrutura, sujeito, determinismo e mudança.

Uma pessoa, segundo Duarte (2003), ao citar Radcliffe-Brown - antropólogo social britânico - é um complexo de relações sociais. Ao contrário, um indivíduo é um organismo biológico que esboça ações e reações fisiológicas e psicológicas, processos e mudanças. Duas dimensões, um único ser. Ao mesmo tempo em que se coadunam, opõem-se. Ocorre que, quando vistos sob uma única perspectiva, tornam-se incompletos. Nesse sentido, há um risco quando programas e/ou políticas públicas se orientam por concepções que prescindam da dimensão pessoa do ser humano.

Quando isso acontece, a experiência da saúde/doença interpela a integralidade da identidade pessoal e impõe ações e reações imobilizadoras de sentido (Duarte, 2003). Ao mesmo tempo, fica sinalizado um modelo estruturalista que estimula o apagamento do sujeito, aqui concebido como um sujeito epistêmico mais complexo e menos fragmentado, como sugere Minayo (2001), ao propor sua construção por meio de debates e de investigações que unam clínica, biologia e saúde pública.

O atual modelo de Reabilitação Profissional circunscrito no âmbito institucional revela certo apagamento do sujeito ${ }^{5}$, parafraseando Minayo (2001), quando afirma que o conhecimento médico e a saúde pública são marcados por esse apagamento ${ }^{6}$. Na

\footnotetext{
${ }^{5} \mathrm{O}$ sujeito é considerado na perspectiva de Jürgen Habermas, que reconhece para ele a possibilidade da ação, mas também da crítica social que traz, como consequência, a capacidade de sentenciar sobre a ação e buscar a transformação (Minayo, 2001).

${ }^{6}$ No modelo de RP praticado pelo INSS, não há espaço para que o/a trabalhador/a seja um agente ativo durante o processo de reabilitação, visto que a própria instituição (INSS) e as empresas determinam onde, 
interlocução entre esses atores que atuam diretamente no processo de RP, é evidente a falta de protagonismo do trabalhador, visto que finda em assumir um papel secundário na própria recuperação/reabilitação, impossibilitado de exercer influência nos processos decisórios e no modus operandi que caracteriza todo o trâmite da RP. Sua invisibilidade, tal qual existente nos contextos de trabalho, que, em muitos casos, são a própria gênese do adoecimento, continua fomentando um ciclo deletério e insalubre que faz emanarem questionamentos acerca da funcionalidade e da resolutividade da RP.

Nesse sentido, Maeno e Vilela (2010) referem como desafiadora a reabilitação profissional de trabalhadores com transtornos psíquicos relacionados ao trabalho, cujas origens e fatores agravantes são heterogêneos e exigem abordagens específicas no processo terapêutico e de reabilitação. Ao fazerem tal reflexão, os autores denunciam a necessidade de abordagens específicas, por natureza, da condição de cada pessoa. As contribuições da Antropologia da Saúde, nesse contexto, podem trazer luz para essa inquietação. Naturalmente, considera-se a complexidade da relação entre saúdetrabalho- doença, particularmente no que se refere a contextos em que os TMC estão presentes. Trata-se de questões relativas à subjetividade, o que, por si só, torna densa a compreensão sobre como se dá essa relação e evidencia a necessidade de lançar mão do olhar da Antropologia da Saúde e sua compreensão sobre saúde e doença como processos socioculturais também permeados pela subjetividade.

Outro aspecto relevante a ser considerado, sobretudo quanto à reabilitação profissional ocasionada por TMC, diz respeito ao estudo etnográfico realizado com egressos de internação psiquiátrica (Silva, 2015). É certo que nem todo trabalhador com diagnóstico de TMC passa, necessariamente, por esse tipo de internação, contudo o estigma que a "doença mental" carrega reverbera na possibilidade de reintegração ao trabalho. Alevato (2011), ao estudar os desafios da reinserção laboral dos afastados por TMC, afirma que ele é:

um campo ainda permeado pelo julgamento preconceituoso de muitos, pela complexidade diagnóstica e formação insuficiente dos profissionais que atuam no atendimento ao trabalhador e, fundamentalmente, pelas representações sociais da

quando e de que forma acontecerá o retorno ao trabalho, muitas vezes, em desacordo com as impressões do próprio trabalhador quanto ao processo como um todo: treinamento para a nova função, indicação da nova função, impedimento de atuar na função anterior etc. (Cestari; Carlotto, 2012; Souza; Queiroz, 2018; Bernardo, 2010). 
loucura e da saúde mental, as quais muitas vezes retardam excessivamente a busca por ajuda (Alevato, 2011: 142).

O estudo etnográfico de Silva (2015), acima referido, alinhado à perspectiva adotada pela Antropologia da Saúde, que superou a relação estática e determinante entre a cultura e os processos de saúde-doença - como atestam trabalhos como os de Arthur Kleinman e Byron Good (Langdon, 2014; Costa; Gualda, 2010) - reflete sobre as contribuições das ciências sociais para se compreender a assistência psiquiátrica, ao destacar a passagem de pessoa para paciente como um aspecto crucial na carreira moral do doente mental. No entanto o referido estudo procurou compreender outro tipo de deslocamento: o de paciente a causo, fazendo menção a pessoas que já foram pacientes psiquiátricos e agora são egressas de internação psiquiátrica (Silva, 2015). Nesse contexto, embora a pessoa retorne ao convívio social, carrega em sua identidade social a alcunha de ex-interna: um causo passível de comentários, estigmas e boatos acerca de sua história por parte da comunidade em que se reinsere, com o agravante de que o “estigma” vinculado à “doença mental” provoca intenso sofrimento (Moraes et al, 2018; Salles; Miranda, 2016). O estudo conclui que portar transtornos mentais é tão relevante no manejo da identidade social estigmatizada quanto portar sobrenomes e apelidos. Não seria essa uma importante reflexão acerca do retorno do/a trabalhador/trabalhadora por ocasião de sua reabilitação? Não passaria a ser um causo com identidade social permeada pela "doença mental", que passa a fazer parte de sua identidade, embora, em muitas situações, nem precise passar por processo de internação, mas apenas ter recebido um diagnóstico de TMC?

A respeito do conceito de reabilitação, Venturini et al. (2003) suscitam uma crítica. Embora os autores reconheçam o valor e o avanço desse processo, sobretudo quando citam a participação dos usuários dos serviços psiquiátricos em encontros e seminários sobre o tema em questão, eles seguem ponderando sobre o aspecto conceitual do termo. Para os autores, o termo refere-se à recuperação de uma função ou de um órgão e traz em sua gênese a influência da medicina geral, que se utiliza de métodos e técnicas direcionadas a essa recuperação.

A grande questão trazida por Venturini et al. (2003) revela uma preocupação quanto ao fato de que esse conceito é constituído de uma expectativa de retorno ao estado original e de uma renormalização. Para os autores, aflora nesse pensamento uma 
dimensão psicológica e mitológica da temporalidade, um valor abstrato, uma ficção intelectual do tempo físico. Ao contrário, propõem uma perspectiva de habilitação - um processo que se desenvolve na riqueza das histórias e das experiências e que, no conto e na reflexão, liberta libertando, afirmam eles. Provoca-se, aqui, um estímulo ao estado de emancipação e protagonismo histórico da pessoa portadora de qualquer tipo de sofrimento mental.

Nesse ponto, para os fins propostos por este estudo, é necessário revisar a concepção da reabilitação e da própria saúde, porque se compreende que há uma relação conceitual intrínseca entre uma e outra. Ou seja, pensar na reabilitação como uma oportunidade de habilitação, como proposto pelos autores supracitados, implica partir de um conceito de saúde que ratifique e corrobore essa concepção. É nesse sentido que as contribuições da Antropologia da Saúde são fundamentais, como veremos adiante.

\section{Saúde e saúde mental no trabalho}

Conceituar saúde, quiçá, compreendê-la, não é uma tarefa fácil. Requer o exercício da escolha de diferentes concepções que tratam do tema e vai além da concepção de simples ausência de doença. Batistela (2007) considera que o modelo biomédico, caracterizado pela ênfase nos aspectos biológicos e individuais e pela abordagem mecanicista, que fragmenta o corpo em sistemas, órgãos, tecidos e células, influencia significativamente, por causa de sua hegemonia, a concepção de saúde para a maioria da população, como o/um "não estar doente".

De acordo com a perspectiva da Organização Mundial de Saúde - OMS (1986), a saúde é apresentada "como um completo estado de bem-estar físico, mental e social, e não, apenas, a ausência de doença ou enfermidade”. Esse conceito tem recebido numerosas críticas, dentre elas, a concepção idealizada de um estado de bem-estar preconizado como ausência de movimento, de dinamicidade. A esse respeito, Coelho e Almeida Filho (2003) afirmam que a saúde é um estado, contudo dinâmico, que pode depender de muitos fatores: do contexto socioeconômico-político-histórico-cultural, do genótipo, do psiquismo, do modo de vida, do aspecto e da situação. Não se trata de compreender nenhum desses aspectos isoladamente, mas a maneira como eles se 
associam e, somente assim, construir um vislumbre da forma como a realidade se apresenta, em particular, nos contextos de saúde e de trabalho.

Outro aspecto importante, assinalado por Dejours (1986), sobre os limites desse conceito proposto pela OMS merece destaque. O autor afirma que a saúde das pessoas é um assunto ligado a elas mesmas. Assim, a subjetividade é reclamada ao se falar em completo estado de bem-estar, como se ele pudesse ser universalizado, estabelecido externamente ao sujeito ${ }^{7}$. Apoiando-se nessa ideia, Simón (1999), ao questionar a definição da OMS, afirma a importância da subjetividade em uma situação, por exemplo, em que seja considerado são um sujeito objetivamente enfermo pela maneira como se apresenta e, apesar de sua enfermidade, demonstre um alto grau de bem-estar. Nessa direção, Scavone (2003) argumenta que o conceito da OMS remete a uma concepção utópica de saúde, porque perde de vista as contradições sociais, econômicas e políticas vinculadas ao processo saúde-doença.

Nesse contexto de múltiplas percepções acerca do tema, o enfoque que o filósofo Georges Canguilhem dá à noção de saúde se refere a ela como "verdade do corpo", ou seja, quando não é explicada por teoremas. Trata-se de uma saúde intrínseca à pessoa. $\mathrm{O}$ autor menciona que a saúde é um conceito vulgar e uma questão filosófica. Vulgar, não no sentido de trivial, mas comum, ao alcance de todos (Canguilhem, 2005).

Ser sadio significa não apenas ser normal numa situação determinada, mas ser, também, normativo, nessa situação e em outras situações eventuais. $O$ que caracteriza a saúde é a possibilidade de ultrapassar a norma que define o normal momentâneo, a possibilidade de tolerar infrações à norma habitual e de instituir normas novas em situações novas (Canguilhem, 2017: 138).

Tanto a perspectiva canguilhemiana de saúde sobre a necessidade de que se considere a capacidade normativa ${ }^{8}$ intrínseca a cada pessoa quanto a concepção dejouriana apresentada anteriormente remetem à ideia de que a saúde não se reduz a uma adaptação a normas, mas, sobretudo, à capacidade normativa da pessoa de ser normativa (produtora de normas).

\footnotetext{
${ }^{7} \mathrm{O}$ sujeito é considerado na perspectiva de Jürgen Habermas, que reconhece para ele a possibilidade da ação, mas também da crítica social que traz, como consequência, a capacidade de sentenciar sobre a ação e buscar a transformação (Minayo, 2001).

${ }^{8}$ A normatividade é compreendida como a capacidade individual de enfrentar o meio e se adaptar a ele (Canguilhem,1995).
} 
Destaca-se, aqui, a importância da VIII Conferência Nacional de Saúde (1986), quanto à contribuição significativa para o avanço da questão da saúde, notadamente quando contempla outros aspectos em sua concepção, como: condições de alimentação, habitação, educação, renda, meio ambiente, trabalho, transporte, emprego, lazer, liberdade, acesso e posse de terra e acesso a serviços de saúde. Remete, inclusive, à influência das formas de organização social da produção sobre a saúde como resultante da combinação dessas dimensões citadas. Lunardi (1999), ao problematizar sobre os conceitos de saúde e analisar esse conceito ampliado, entre outros aspectos, critica a possível perda de referência dos aspectos biológicos e psíquicos da enfermidade bem como certa exclusão da análise dos processos de saúde/doença, de quaisquer outros fatores que não tenham caráter social.

É preciso ressaltar os méritos propostos pelos dois organismos em relação ao conceito de saúde. De um lado, a OMS, que apresenta dimensões múltiplas do ser humano; de outro, a ampliação do conceito de saúde definido na VIII Conferência Nacional de Saúde, que favorece uma importante articulação entre saúde e sociedade. Mediante o exposto, deparamo-nos com o desafio de construir uma reflexão que considere tanto as questões sociais na constituição da saúde quanto os aspectos biológicos e psíquicos, a subjetividade e o protagonismo do sujeito no processo saúdedoença, como atestam estudos da área da Antropologia da Saúde (Sarti, 2010; Costa; Gualda, 2010; Santos et al, 2012; Nunes, 2014).

Quando a saúde é pensada no(s) contexto(s) do trabalho, aspectos peculiares se inserem nessa já tão densa reflexão. Ocorre que, no(s) mundo(s) do trabalho, fenômenos como a reestruturação produtiva podem interferir na capacidade normativa dos trabalhadores/trabalhadoras, de modo a influenciar sobremaneira suas concepções acerca da relação entre trabalho, corpo e saúde, assim como o próprio conceito do processo saúde-doença. Tal realidade pode ser compreendida com Dejours (2012), quando faz referência à implicação do sujeito que trabalha, a partir dos "gestos, do saber-fazer, do engajamento do corpo, da mobilização da inteligência, da capacidade de refletir, de interpretar e de reagir a diferentes situações, manifestando seu poder de sentir, pensar, inventar etc.” (Dejours, 2012: 24).

Em referência à relação entre saúde, doença e trabalho, Esponda (2012), em um estudo realizado em Buenos Aires com trabalhadores de uma siderúrgica, concluiu que a 
hegemonia neoliberal e a desindustrialização expressas através das novas formas de organizar o trabalho, a terceirização, as subcontratações, dentre outras formas de precarização, exercem influência importante sobre a concepção que os trabalhadores/trabalhadoras passam a ter sobre a saúde, o corpo e o próprio trabalho. Além disso, a pesquisadora sinaliza que, entre outros resultados, percebe-se o aumento tendencial das "doenças mentais" relacionadas ao trabalho.

Outro estudo realizado no Chile por Salazar (2012), em empresas de Call Centers, para explorar novas formas de produção, aponta para o que a autora denomina de "capitalismo cognitivo", em referência a essas novas formas de trabalho, e salienta a utilização por parte do capital das capacidades subjetivas e da força de trabalho, manifestadas na exploração das habilidades de comunicação, tendo em vista a natureza daquela atividade. Acrescenta, ainda, que esse tipo de prestação de serviço se configura como uma "nova forma de estranhamento, de captura das capacidades subjetivas, centrada em uma habilidade humana básica: a fala" (Salazar, 2012: 286). Trata-se, segundo a autora, de uma exploração das habilidades e capacidades emocionais e de comunicação que geram sérios desdobramentos na saúde desses trabalhadores, corroborando a ideia de Alves (2011), já citado anteriormente, no que se refere à captura da subjetividade. Para tanto, confere aos dispositivos utilizados pelo novo modelo de gestão, o toyotismo, o potencial de conduzir a ação e o pensamento do trabalhador, ao alcance dos objetivos e dos anseios organizacionais.

É nesse denso e enigmático cenário do trabalho que se instala o sofrimento psíquico, emoldurado pelas tramas dos novos modos de produção, neste estudo, brevemente discutidos. As demandas psíquicas envoltas em discursos e expectativas quanto à produtividade e ao engajamento do trabalhador, sob a égide de paradigmas travestidos de expressões como "vestir a camisa" da organização, compõem estruturas rígidas e controladoras em que se inserem os trabalhadores.

Em um estudo exploratório e multicêntrico como proposta para a construção de rotinas de atendimento em Saúde Mental e Trabalho em pessoas atendidas no Sistema Único de Saúde (SUS) no Brasil, os autores reconhecem que "é necessário mudar o olhar, quando se trata de buscar identificar o sofrimento psíquico do trabalho" (Merlo et al., 2016:49). Para eles, a intervenção no contexto da relação entre trabalho e saúde mental requer ferramentas específicas que possam promover a compreensão dessa 
relação. Os estudos na área da Antropologia da Saúde, interdisciplina, que recorre, como já explicitado, às contribuições das ciências sociais e das ciências da saúde para compreender o processo saúde-doença, numa perspectiva biopsico-históricosociocultural (Minayo, 1998), produz um conhecimento que nos auxilia nessa empreitada. Minayo (1998: 35) enuncia que o papel da Antropologia seria o de restituir aos fenômenos biológicos sua verdadeira natureza social, destruindo a indevida “naturalização" empreendida pela ciência, sobretudo pela Biologia e pela Medicina.

Aqui se pretende evidenciar o antagonismo existente entre uma concepção de saúde que remete à autonomia pessoal e um modelo produtivo que preconiza a fragilização da autonomia individual. A autonomia citada insere-se no conceito de individuação proposto por Habermas, que prevê uma interação do indivíduo com seu meio social, no interior de um processo de racionalidade, e que almeja um grau maior de pureza e de competência comunicativa (Queiroz, 2005).

Não estaria a reestruturação produtiva alavancando uma cultura no interior das fábricas, das empresas, das prestadoras de serviços e nos mais diversos contextos de trabalho? A cultura é aqui mencionada nos mesmos termos aos que se referem Langdon e Wiik (2010: 175), como um

conjunto de elementos que mediam e qualificam qualquer atividade física ou
mental, que não seja determinada pela biologia, e que seja compartilhada por
diferentes membros de um grupo social. Trata-se de elementos sobre os quais
os atores sociais constroem significados para as ações e interações sociais
concretas e temporais, assim como sustentam as formas sociais vigentes, as
instituições e seus modelos operativos. A cultura inclui valores, símbolos,
normas e práticas.

Para os autores, trata-se de um conceito basilar da Antropologia e um instrumental para qualquer profissional da saúde que atue ou faça pesquisa. De acordo com tal afirmação, destaca-se a importância de considerar as influências que os novos modelos de produção exercem na dinâmica de construção cultural no interior das organizações e instituições e, como consequência, nos processos de reabilitação profissional em saúde mental, objeto central deste estudo.

\section{Antropologia da Saúde e Reabilitação Profissional em Saúde Mental}


Sem nenhuma reserva, importa ressaltar a existência de muitos desafios quando se trata de Reabilitação Profissional em Saúde Mental, alguns já postos no decorrer deste ensaio teórico, porém distantes de alcançar uma realidade ainda em vias de descortinamento. A esse respeito, Athayde (2011:348) refere-se ao próprio campo da saúde do trabalhador apontando suas limitações e "encaminhamentos ainda frágeis, especialmente quanto ao foco em saúde mental". Indubitavelmente, um desafio ainda maior.

A Antropologia da Saúde apresenta, em seu escopo teórico, conceitos e interrelações conceituais que podem trazer luz ou contribuir substancialmente com o desvendamento da, ainda obscura, relação entre Reabilitação Profissional e Saúde Mental. No Brasil, suas contribuições para os estudos sobre saúde, cultura e sociedade têm se multiplicado (Langdon; Wiik, 2010). Essa interdisciplina, como já salientado, não perde de vista a inter-relação entre os aspectos psicossociais, econômicos, históricos, biológicos e culturais e concebe o processo saúde-doença como amplo e complexo (Costa; Gualda, 2010).

Martínez-Hernáez e Correa-Urquiza (2017) enunciam que a saúde coletiva é um campo consolidado na América Latina que provocou mudanças não só no que se refere às teorias e às práticas, mas também no modo de pensar sobre elas. A saúde mental coletiva, por sua vez, como advertem os referidos autores, tem se destacado em alguns países, como o Brasil e a Argentina. O diálogo estabelecido com a Antropologia da Saúde, nesse contexto, tem sido fundamental, porque

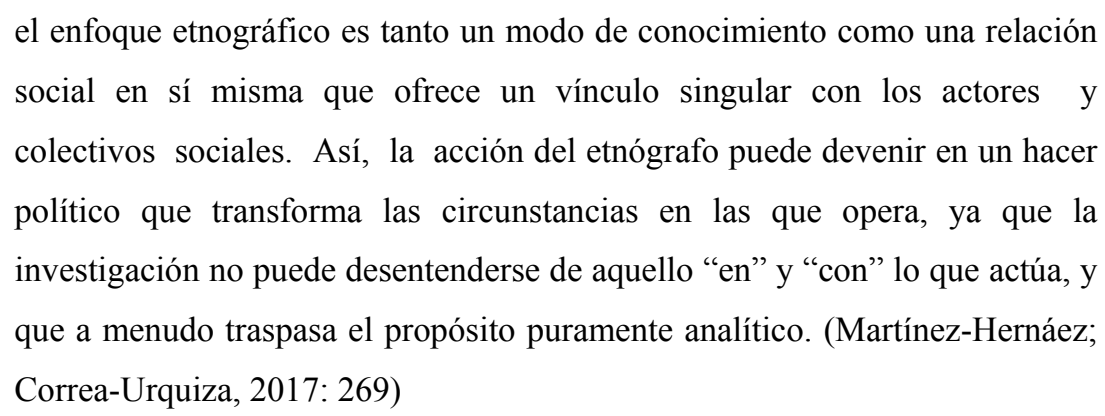

No processo de reabilitação profissional, esse resgate da "natureza social" pode ampliar a compreensão da realidade e das variáveis que o compõem. Nesse sentido, o retorno a uma atividade laboral passa a ser visto como um todo, que não só envolve uma dimensão meramente utilitária, como também transcende e avança para uma visão de ser humano total. Objetivamente a perspectiva de cultura como um conceito 
instrumental, assim tratado por Langdon e Wiik (2010), pode favorecer a compreensão tanto de coletivos de trabalho quanto individualmente, no contexto da Reabilitação Profissional em Saúde Mental.

O que se pretende afirmar é o fato de que reabilitar-se ou habilitar-se, como ambicionam Venturini et al. (2003), levando-se em consideração as características culturais tanto das pessoas envolvidas quanto das organizações e das comunidades onde estão inseridas ou de que poderão fazer parte, pode favorecer a que, verdadeiramente, o sujeito possa ser (ou voltar a ser) protagonista daquele momento histórico da própria vida.

Os eventos que ocorrem em nossa vida provocam reações e suscitam-nos uma adaptação que envolve o corpo, o humano integralmente. Naturalmente pode soar estranho a um estudo que envolve saúde mental lançar mão de um viés teóricoconceitual relacionado ao corpo, sobretudo quando o modelo biomédico que se volta para a unicausalidade e a dimensão biológica do humano ainda se percebe hegemônico em muitas esferas da relação saúde/doença, como já ressaltado. Apesar disso, é possível que conceber esse corpo sob olhar que o amplia, estende-o e enriquece. De acordo com Rodrigues (2005), a antropologia do corpo estabelece conhecimentos que o autor denomina de cristalinos: de que o corpo humano é menos biológico do que se pensava, de que é menos individual do que costuma postular a cultura individualista e que sua compreensão não mais se limita à sua dissecação em laboratórios. Afinal, como ressaltam Costa e Gualda (2010: 930), nessa perspectiva, defende-se que os sujeitos são capazes de superar os limites biológicos do corpo e a compreensão biomédica, "considerando-os sujeitos que refletem e vivenciam a experiência subjetiva no processo saúde-doença, tendo-se em conta a organização social e econômica em que estão inseridos." O corpo é também socialmente construído e apresenta características dos fenômenos culturais. Como dissociá-lo dos fenômenos psíquicos?

Assim, a noção de corpo, nessa perspectiva antropológica, pode favorecer os processos de reabilitação em saúde mental e consubstanciar uma dimensão relacional entre "mente e corpo", claramente dissociada na perspectiva cartesiana e fortalecida na perspectiva do modelo biomédico, o que fraciona o sujeito enquanto segue a lógica disciplinar presente no campo científico (Rodrigues, 2005; Costa; Gualda, 2010; Bellaguarda; Padilha; Argenta; Borenstein, 2011; Sarti, 2010). Tavares (2017:215) 
afirma que nós não "somos nossos corpos, nós fazemos o nosso corpo". Tal compreensão contribui para problematizar as relações entre "subjetividade, emoção e corpo, considerando as diferenças intensivas ou os devires."

A questão da saúde, na perspectiva da Antropologia da Saúde, já tratada brevemente neste artigo, também representa um conceito relevante no fortalecimento da retomada da vida laboral dos/as trabalhadores/trabalhadoras acometidos/as por TMC. Avançando nessa discussão, Langdon (2014), em estudo que trata de diálogos da Antropologia com a saúde, apresenta esta última a partir de perspectivas distintas: a saúde como experiência e construção sociocultural - salientando a importância dos processos simbólicos, dos signos, da experiência psicossocial e da própria cultura para se compreender o processo saúde/doença e a saúde como política. Para essa autora, a inter-relação com a saúde coletiva e sua crítica sobre o enfoque reducionista da biomedicina contribuíram para o interesse antropológico na saúde.

No que concerne à saúde como política, sustenta-se em eixos distintos, entre os quais, situam-se as "dinâmicas envolvidas nas práticas de autoatenção empreendidas pelos sujeitos em contextos etnográficos específicos, ressaltando as relações dessas práticas com processos sociocosmológicos e vivenciais" (Langdon, 2014: 1026). O interesse em destacar a autoatenção e relacionar com o processo de reabilitação diz respeito ao fato de que a primeira aponta para o reconhecimento da autonomia e da criatividade da coletividade. Aqui se salienta a importância de que essa dinâmica seja percebida e melhor compreendida nas vivências de reabilitação profisssional, tendo em vista que a autonomia de que se trata neste texto fala de uma possível articulação de recursos terapêuticos acessíveis, independentemente de sua origem, e da criação de articulações novas (Langdon,2014).

Evidentemente, os conceitos e as possíveis contribuições da Antropologia da Saúde para o processo de Reabilitação Profissional em Saúde Mental não se esgotam nesta breve discussão conceitual. O que se pretendeu aqui foi esboçar uma reflexão acerca, minimamente, de uma característica que perpassa a Antropologia, o campo saúde do trabalhador e a saúde mental relacionada ao trabalho: a interdisciplinaridade. Seguramente, é ela que favorece esse diálogo, de certo, ainda incipiente, contudo, promissor. Se, de um lado, a relação saúde mental e trabalho é um campo em permanente construção e enigmático quanto o próprio mundo do trabalho, de outro, é 
necessário lançar mão de dispositivos e diálogos que possam iluminar e apontar caminhos não somente para se compreender essa realidade, mas também, para construir mecanismos e políticas públicas que tragam o sujeito, o trabalhador, para o centro da dinâmica de retorno ao trabalho no contexto da reabilitação profissional em saúde mental, uma apologia ao protagonismo.

O usuário interfere tanto quanto todos os demais profissionais de saúde nos processos de cuidado. Ele não é um objeto a que se destinam as políticas, mas ele ou ela interfere criativamente, reconfigurando, surpreendendo, problematizando, enfim, "trazendo o sistema à vida" (numa analogia com a feliz expressão de Ingold, 2012), o que faz com que todos produzam interferências no curso dos acontecimentos. (Tavares, 2017: 219, grifo da autora).

Costa e Paulon (2012) entendem que é preciso diferenciar o conceito de protagonismo de uma concepção limitada de autonomia, muito próxima da "solidão individualista". Protagonizar significa recriar as possibilidades de criar novas normas de vida por meio da participação coletiva. No entanto, é necessário saber qual o tipo de participação social que fomenta o protagonismo. Como defendem os referidos autores, é preciso construir espaços participativos potentes, em que o diálogo possa trazer à tona a diversidade dos encontros e dos discursos e que os sujeitos possam experienciar, no coletivo, a reflexão, o sentimento e a decisão, "imperativo ético para toda política pública."

\section{Considerações finais}

Este ensaio teórico não pretendeu apenas descrever a dinâmica da Reabilitação Profissional em Saúde Mental que ora se estabelece no Brasil, via INSS, mas também refletir acerca de um caminho que, embora não seja único, é profícuo para o processo em questão e se refere às contribuições que a Antropologia da Saúde pode oferecer para fortalecer tanto os alicerces conceituais quanto as políticas públicas que alcançam os/as trabalhadores/trabalhadoras submetidos à reabilitação.

Os transtornos mentais e comportamentais têm vitimado muitos trabalhadores e trabalhadoras neste país e alcançam lugares expressivos nas estatísticas nacionais como 
uma das principais causas de afastamento do trabalho. Por outro lado, observa-se um descompasso entre o crescimento dos $\mathrm{TMC}$ e as práticas de políticas públicas de saúde, particularmente, no que se refere à complexa relação entre saúde mental e trabalho. $\mathrm{O}$ modelo biomédico hegemônico segue minimizando o papel do sujeito e assumindo isoladamente o diagnóstico e o prognóstico, o que implica os desdobramentos da vida do/a trabalhador/trabalhadora, incluindo sua trajetória laboral. A reabilitação profissional, à qual são submetidas as pessoas afastadas, demonstra não atentar para as particularidades dos TMC, ao mesmo tempo em que a concepção de saúde e o modelo biomédico, como já evidenciado, ainda influentes no interior de sua trajetória, acabam por sinalizar a necessidade de que seja revista não somente sua dinâmica, como também sua resolutividade, sobretudo no que se refere à reinserção na vida laboral.

Naturalmente, há que se considerar a importância do que tem sido feito em termos de reabilitação profissional e, ao mesmo tempo, reconhecer os desafios contidos nos contextos que envolvem a saúde mental relacionada ao trabalho, aspectos brevemente discutidos neste estudo, mas reconhecidos como fatores de extrema relevância, contudo, na mesma medida, sinalizar a necessidade de ampliar o espectro conceitual. Daí a provocação quanto às contribuições da Antropologia da Saúde.

É preciso que os conceitos basilares, como citado anteriormente, possam ganhar vulto nas discussões acadêmicas e institucionais - se através de pesquisas, de produção científica teórico-metodológicas ou por outras vias. Pretende-se que os aspectos culturais sejam concebidos como influentes, que a noção de corpo e sua estreita relação com a dinâmica psíquica possam ser contempladas e que a reflexão sobre saúde seja trazida à baila como um processo - o processo saúde/doença - e que os aspectos psicossociais inerentes a esse processo sejam percebidos e sinalizados como constituintes da reabilitação.

Não se pretende, em absoluto, esgotar esta discussão, mas tão somente contribuir para provocar uma reflexão, articulada às contribuições da Antropologia da Saúde, que, certamente, demanda uma maior investigação no universo da saúde mental, relacionada ao trabalho, às políticas públicas voltadas para a reabilitação profissional, esta última atenta aos TMC. Uma relação efetivamente dialética, que não se pretende completa, mas contínua. 
Ao invés de falar da possível natureza utópica dessas reflexões, é preferível esta outra:

A utopia está lá no horizonte. Me aproximo dois passos, ela se afasta dois passos. Caminho dez passos e o horizonte corre dez passos. Por mais que eu caminhe, jamais alcançarei. Para que serve a utopia? Serve para isso: para que eu não deixe de caminhar.

Eduardo Galeano

\section{REFERÊNCIAS}

ALEVATO, Hilda. Os desafios da reinserção laboral dos afastados por transtornos mentais e comportamentais. Estudos do Trabalho. Ano V. n.9. p.139-162, 2011.

ALVES, Giovanni. Trabalho e subjetividade - o espírito do Toyotismo na era do capitalismo manipulatório. São Paulo: Boitempo, 2011.

ANTUNES, Ricardo. Desenhando a nova morfologia do trabalho e suas principais manifestações. In: MENDES, Ana M., MORAES, Rosângela D. \& MERLO, Álvaro R.C. (orgs.). Trabalho \& Sofrimento - Práticas Clínicas e Políticas, p. 25-45. Curitiba: Juruá, 2014.

ANTUNES, Ricardo; PRAUN, Luci. A sociedade dos adoecimentos no trabalho. Serviço Social \& Sociedade, São Paulo, n. 123, p. 407-427, jul/set. 2015.

ATHAYDE, Milton. Saúde "mental" e trabalho: questões para discussão no campo da saúde do trabalhador. In: Saúde do Trabalhador na Sociedade Brasileira Contemporânea. MINAYO Gomes, C., MACHADO, Jorge M.H. e PENA, Paulo G.L. (orgs.). Rio de Janeiro, Fiocruz, 2011.

BARBOSA, Atilla Magno S. Engajamento subjetivo e organização flexível do trabalho: o caso dos trabalhadores da indústria do alumínio primário paraense. Sociedade e Estado. Brasília, v. 29, n. 1, p. 225-252, 2014.

BATISTELLA, Carlos. Abordagens contemporâneas do conceito de saúde. In FONSECA, Angélica F. e CORBO, Anamaria D. (orgs.) O Território e o Processo Saúde Doença. Rio de Janeiro: EPSJV/Fiocruz, 2007.

BELLAGUARDA, Maria Lígia R. et al. O corpo humano numa aproximação à antropologia da saúde. Revista Mal Estar e Subjetividade, v. XI, n. 3, p. 1089-1103, 
2011. Disponível em http://pepsic.bvsalud.org/pdf/malestar/v11n3/09.pdf. Acesso em 26/02/2020.

BERNARDO, Lilian D. Os significados do trabalho e da reabilitação profissional para o trabalhador incapacitado para o exercício da profissão habitual. Cadernos Brasileiros de Terapia Ocupacional da UFSCar. v. 18, n. 13, p. 313-315, 2010. Disponível em http://www.cadernosdeterapiaocupacional.ufscar.br/index.php/cadernos/article/view/386 /300. Acesso em 26/02/2020.

BRASIL. Previdência, Ministério da Economia. Dê sua colaboração: INSS abre consulta pública sobre reabilitação profissional. Disponível em http://www.previdencia.gov.br/2014/02/de-sua-colaboracao-inss-abre-consulta-publicasobre-reabilitacao-profissionai/ Acesso em 27/11/2019.

BRASIL. Ministério da Previdência Social. Anuário Estatístico de Acidentes do Trabalho 2017. Disponível em http://sa.previdencia.gov.br/site/2018/09/AEAT2017.pdf. Acesso em 29/10/2019.

CANESQUI, Ana Maria. Os estudos de antropologia da saúde/doença no Brasil na década de 1990. Ciência \& Saúde Coletiva, vol.8, n. 1, p.109-124, 2003. Disponível em https://www.researchgate.net/publication/26370262. Acesso em 02/03/2020.

CANGUILHEM, Georges. Escritos sobre a Medicina. Forense Universitária: Rio de Janeiro, 2005. , Georges. O normal e o patológico. Rio de Janeiro: Forense, 2017.

CESTARI, Elisabete; CARLOTTO, Mary Sandra. Reabilitação Profissional: o que pensa o trabalhador sobre sua reinserção. Estudos e pesquisas em psicologia. Vol. 12, n.1, p. 93-115, 2012. Disponível em https://doi.org/10.12957/epp.2012.8307. Acesso em $26 / 02 / 2020$.

COELHO, Maria Teresa A. D.; ALMEIDA FILHO, Naomar. Análise do conceito de saúde a partir da epistemologia de Canguilhem e Foucault. In: GOLDEMBERG, Paulete; GOMES, Mara H.A. \& MARSIGLIA, Regina M. G. (Orgs.) O clássico e o novo: tendências, objetos e abordagens em ciências sociais e saúde. Rio de Janeiro: Fiocruz, 2003.

COSTA, Gabriela M. C.; GUALDA, Dulce M. R. Antropologia, etnografia e narrativa: caminhos que se cruzam na compreensão do processo saúde-doença. Hist. cienc. saude-Manguinhos [online]. vol.17, n.4, p. 925-937, 2010. Disponível em https://doi.org/10.1590/S0104-59702010000400005.Acesso em 21/02/2020.

COSTA, Diogo F. C.; PAULON, Simone M. Participação Social e protagonismo em saúde mental: a insurgência de um coletivo. Saúde em Debate, v. 36, n. 95, p. 572582,2012 Disponível em https://www.ufrgs.br/intervires/wpcontent/uploads/2015/06/COSTA-PAULON-Participa\%C3\%A7\%C3\%A3o-Social-eprotagonismo-em-sa\%C3\%BAde-mental.pdf Acesso em 21/02/2020.

DACHS, José N. W.; BAMBAS, Alexandra; CASAS, Juan A. Determinantes sociais e econômicos de desigualdades em saúde na América Latina e no Brasil In: MINAYO, Maria C.S.; COIMBRA JR., Carlos E.A. (orgs.). Críticas e Atuantes: ciências sociais e 
humanas em saúde na América Latina. Rio de Janeiro: Ed. Fiocruz, p. 333-354, 2005. Disponível em https://static.scielo.org/scielobooks/w5p4j/pdf/minayo9788575413920.pdf. Acesso 02/03/2020.

DEJOURS, Christophe. Por um novo conceito de saúde. Revista Brasileira de Saúde Ocupacional. n.54. v.14, 1986.

DEJOURS, Christophe. Trabalho e emancipação. Tradução: Franck Soudant - Brasília: Paralelo 15, 2012.

DUARTE, Luiz Fernando D. Indivíduo e pessoa na experiência da saúde e da doença. Ciência e Saúde Coletiva, v.8, n.1, p.173-183, 2003.

ESPONDA, María A. Trabajo y salud em los años de la reestructuración productiva. El caso de los trabajadores de la ex Propulsora Siderúrgia, Ensenada, Buenos Aires. Cadernos de Campo, São Paulo, n.21, p.1-360, 2012.

FRANCO, Tânia; DRUCK, Graça; SELIGMANN-SILVA, Edith. As novas relações de trabalho, o desgaste mental do trabalhador e os transtornos mentais no trabalho precarizado. Revista Brasileira de Saúde Ocupacional, São Paulo. v. 35, n. 122, p. 229$248,2010$.

HIRATA, Helena. Novas configurações da divisão sexual do trabalho. Cadernos de Pesquisa FCC. São Paulo, v. 37, n. 132, p. 595-609, set./dez, 2007.

IBRAHIM, Fábio Z. Curso de Direito Previdenciário. Rio de Janeiro: Impetus, 2012.

LACAZ, Francisco A.C. O Campo Saúde do Trabalhador: resgatando conhecimentos e práticas sobre as relações trabalho-saúde. Caderno Saúde Pública. Rio de Janeiro (757766), 2007.

LACAZ, Francisco A.C. Qualidade de vida no trabalho e saúde do trabalhador: uma visão crítica. In: GOLDEMBERG, Paulete; GOMES, Mara. H. A.; MARSIGLIA, Regina M. G. (Orgs.) O clássico e o novo: tendências, objetos e abordagens em ciências sociais e saúde. Rio de Janeiro: Fiocruz, 2003. p. 413-429.

LANCMAN, Selma. O mundo do trabalho e a psicodinâmica do trabalho. In: LANCMAN, Selma. \& SZNELWAR, Laerte I. (orgs.). Christophe Dejours. Da psicopatologia à psicodinâmica do trabalho, p.24-27. Rio de Janeiro: Fiocruz, Brasília: Paralelo 15, 2004.

LANCMAN, Selma; BARROS, Juliana O; JARDIM, Tatiana A. Teorias e práticas de retorno e permanência no trabalho: elementos para a atuação dos terapeutas ocupacionais. Revista Terapia Ocupacional da Universidade de São Paulo, v. 27, p. 101108, 2016. Disponível em http://dx.doi.org/10.11606/issn.2238-6149.v27i2p101-108. Acesso em 27/02/2020.

LANGDON, Ester J.; FOLLÉR, Majer-Lis; MALUF, Sonia W. Um balanço da antropologia da saúde no Brasil e seus diálogos com as antropologias mundiais. Anuário Antropológico [Online], p. 51-89, 2012. Disponível em http://journals.openedition.org/aa/254. DOI 10.4000/aa.254. Acesso em 02/03/2020. 
LANGDON, Esther J. Os diálogos da Antropologia com a Saúde: contribuições para as políticas públicas. Ciência e Saúde Coletiva. v.19, n.4, p.1019-1029, 2014.

LANGDON, Esther J. e WIIK, Flavio B. Antropologia, saúde e doença: uma introdução ao conceito de cultura aplicado às ciências da saúde. Rev. Latino-americana de Enfermagem. v.18, n.3: maio-junho, 2010.

LUNARDI, Valéria L. Problematizando conceitos de saúde, a partir do tema da governabilidade dos sujeitos. Rev. Gaúcha Enfermagem, Porto Alegre, v.20, n.1, p.2640, jan, 1999.

MARRONI, Denize. A importância da antropologia na saúde. Saúde Coletiva, v.4, n.16, p. 103, Ed. Bolina: São Paulo, Brasil, 2007. Disponível em https://www.redalyc.org/pdf/842/84201602.pdf. Acesso em 02/03/2020.

MARTÍNEZ-HERNÁEZ, Angel; CORREA-URQUIZA, Martín. Un saber menos dado: nuevos posicionamientos en el campo de la salud mental colectiva. Salud Colectiva. v. 13, n. 2, p. 267-278. 2017. Disponível em http://revistas.unla.edu.ar/saludcolectiva/article/view/1168/1184 Acesso em 21/02/2020. doi: $10.18294 /$ sc.2017.1168.

MENENDÉZ, Eduardo L. Antropología Médica en América Latina 1990-2015: Una revisión estrictamente provisional. Salud Coletiva, vol.14, n. 3, p. 461-481, 2018. Disponível em https://pesquisa.bvsalud.org/portal/resource/pt/biblio-979109. Acesso: $02 / 03 / 2020$.

MAENO. Maria, \& VILELA, Rodolfo A. G. Reabilitação profissional no Brasil: elementos para a construção de uma política pública. Revista Brasileira de Saúde Ocupacional, 35, 0303-7657, 2010.

MERLO, Álvaro R.C.; BOTTEGA, Carla G.; PEREZ, Karine V. Saúde mental e trabalho no Brasil: a questão da atenção no Sistema Único de Saúde. Revista Trabalho (Em)Cena. Vol.01, n.2, pp.49-59, 2016.

MINAYO, Maria C.S. Construção da identidade da Antropologia na área de saúde: o caso brasileiro. In: ALVES, Paulo C. \& RABELO, Maria C. (orgs.). Antropologia da Saúde: traçando identidades e explorando fronteiras. Rio de Janeiro: Editora Fiocruz/ Editora Relume Dumará, 1998. p. 29-46

MINAYO, Maria C. S. Estrutura e sujeito, determinismo e protagonismo histórico: uma reflexão sobre a práxis da saúde coletiva. Ciência \& Saúde Coletiva, v.6 n.1:p. 719, 2001.

MORAES, Ludmila Nunes et al. A loucura e a sua verdade em questão: discursos de profissionais de Enfermagem da atenção hospitalar. Revista Portuguesa de Enfermagem de Saúde Mental. v. 19, p. 27-36. 2018 Disponível em

http://www.scielo.mec.pt/pdf/rpesm/n19/n19a04.pdf Acesso em 23 de janeiro de 2020, doi: 10.19131/rpesm.0199 
NUNES, Mônica de Oliveira. Da aplicação à implicação na antropologia médica: leituras políticas, históricas e narrativas do mundo do adoecimento e da saúde. História, Ciências, Saúde - Manguinhos, v.21, n.2, p.403-420, 2014. Disponível em http://www.scielo.br/pdf/hcsm/v21n2/0104-5970-hcsm-21-2-0403.pdf Acesso em $\underline{21 / 02 / 2020 .}$.

ORGANIZAÇÃO MUNDIAL DE SAÚDE - OMS. (2011). World Report on Disability (Relatório mundial sobre a deficiência). The World Bank. Acesso em 03 de março de $2020 \mathrm{de}$ http://www.who.int/disabilities/world_report/2011/chapter4_por.pdf?ua=1

PUTTINI, Rodolfo F.; PEREIRA Júnior., A.; OLIVEIRA, Luiz R. Modelos explicativos em saúde coletiva: abordagem biopsicossocial e auto-organização. Physis: Revista de Saúde Coletiva, 20(3), 753-767, 2010.

QUEIROZ, Marcos S. Antropologia, saúde e medicina: uma perspectiva teórica a partir da Teoria da Ação Comunicativa de Habermas. In: Críticas e atuantes: ciências sociais e humanas em saúde na América Latina. MINAYO, Maria C.S. e JÚNIOR, Carlos E.A.C. (orgs.) Rio de Janeiro: Editora Fiocruz, p. 109-129, 2005.

RODRIGUES, José C. Os corpos na Antropologia. In: Críticas e atuantes: ciências sociais e humanas em saúde na América Latina. MINAYO, Maria C.S. e JÚNIOR, Carlos E.A.C. (orgs.) Rio de Janeiro: Editora Fiocruz, p. 157-182, 2005.

SALAZAR, Areli E. Materialidad y subjetividad del trabajo: apuntes preliminares sobre los call centers em Chile. Cadernos de Campo. São Paulo, n. 21, p. 273-287, 2012.

SALLES, Anna Carolina Rozante Rodrigues; MIRANDA, Lilian. Desvincular-se do manicômio, apropriar-se da vida: persistentes desafios da desinstitucionalização. Psicologia \& Sociedade, v. 28, n. 2, p. 369-379, 2016. Disponível em http://www.scielo.br/pdf/psoc/v28n2/1807-0310-psoc-28-02-00369.pdf. Acesso em 30 de janeiro de 2020.

SANTOS, Alessandra Carla Baia et al. Antropologia da saúde e da doença: contribuições para a construção de novas práticas em saúde. Rev. NUFEN [online]. v.4, n.2, $\quad$ p. 11-20, 2012. Disponível em http://pepsic.bvsalud.org/scielo.php?script $=$ sci arttext\&pid $=S 2175-$ $\underline{25912012000200003}$. Acesso em 19/09/2017.

SANTOS, Wederson. Pessoas com deficiência e inclusão no trabalho na América Latina: desafios à universalização dos direitos. Caderno Brasileiro de Terapia Ocupacional, São Carlos, v.25, n.4, p.839-854, 2017. Disponível em http://www.cadernosdeterapiaocupacional.ufscar.br/index.php/cadernos/article/view/166 8. Acesso em 02/03/2020.

SARTI, Cynthia. Corpo e doença no trânsito de saberes. RBCS, v. 25, n 74, p. 77-91, 2010. Disponível em http://www.scielo.br/pdf/rbcsoc/v25n74/a05v2574.pdf Acesso em 21/02/2020.

SCAVONE, Lucila. Das diferenças às desigualdades: reflexões sobre o conceito 
de saúde reprodutiva nas ciências sociais. In: GOLDEMBERG, Paulete; GOMES, Maria H.A.; MARSIGLIA, Regina M. G. (Orgs.) O clássico e o novo: tendências, objetos e abordagens em ciências sociais e saúde. Rio de Janeiro: Editora Fiocruz, p. 187-195, 2003.

SELIGMANN-SILVA, Edith. Saúde mental no trabalho contemporâneo. In: Anais do $9^{\circ}$ Congresso Internacional de Stress da ISMA-BR. Porto Alegre/RS, 2009.

SELIGMANN-SILVA, Edith. Trabalho e desgaste mental: o direito de ser dono de si mesmo. São Paulo: Cortez, 2011.

SILVA, Martinho B.B. De paciente a causo: uma etnografia com egressos de internação psiquiátrica. Ciência \& Saúde Coletiva, v.20, n.2: p.353-362, 2015.

SILVA, Mauri A. Os reflexos da crise econômica sobre os direitos trabalhistas no Brasil. Revista Katálysis, v. 22, n.2: p.252-272, 2019.

SIMÓN, Miguel A. Manual de Psicologia de La Salud - Fundamentos, metodología y aplicaciones. Biblioteca Nueva. Madrid, España, 1999.

SIMONELLI, Ângela P.; CAMAROTTO, João A.; BRAVO, Ecléa S., \& VILELA, Rodolfo A. G. Proposta de articulação entre abordagens metodológicas para melhoria do processo de reabilitação profissional. Revista Brasileira de Saúde Ocupacional, v. 35, n.121, p.64-73, 2010.

SOUZA, Andréa D. S. \& QUEIRÓZ, Maria de Fátima F. Percepção dos trabalhadores inseridos na reabilitação profissional do Instituto Nacional do Seguro Social: a organização do trabalho adoece? v. 42, n. 116, p. 100-112, 2018. Revista Saúde em Debate. Disponível em https://www.scielosp.org/pdf/sdeb/2018.v42n116/100-112 DOI: 10.1590/0103-1104201811608. Acesso em 26/02/2020.

TAKAHASHI, Mara A. B. C. \& IGUTI, Aparecida M. As mudanças nas práticas de reabilitação profissional da Previdência Social no Brasil: modernização ou enfraquecimento da proteção social? Cadernos de Saúde Pública, v.24, n.11, p. 2661$2670,2008$.

TAVARES, Fátima. Rediscutindo conceitos na antropologia da saúde: notas sobre os agenciamentos terapêuticos. MANA v. 23, n. 1 p. 201-228, 2017 - DOI http://dx.doi.org/10.1590/1678-49442017v23n1p201. Disponível em: http://www.scielo.br/pdf/mana/v23n1/1678-4944-mana-23-01-00201.pdf. Acesso em 28/02/2020.

VENTURINI, Ernesto; GALASSI, Alba; RODA, Annalisa. \& SÉRGIO, Ennio. Habilitar-se em saúde mental: observações críticas ao conceito de reabilitação. Arquivos Brasileiros de Psicologia, v.55, n.1, p.56-63, 2003.

Recebido 16/03/2020

Aprovado 10/04/2020 